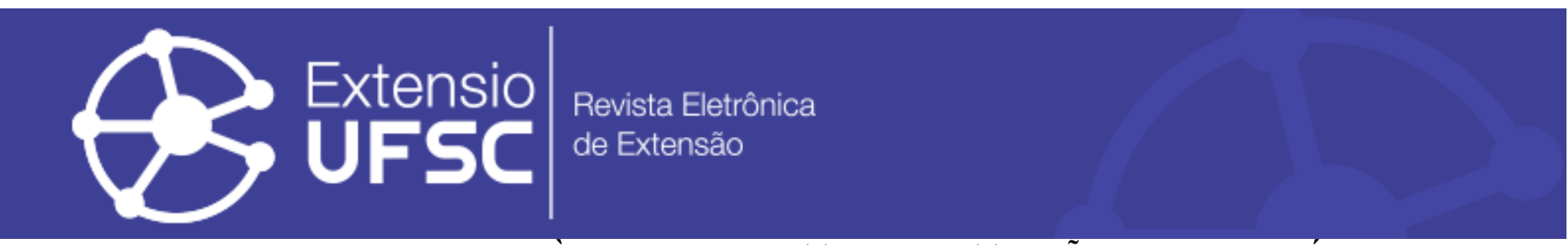

\title{
ECONOMIA VAI À ESCOLA: RELATOS DE EXTENSÃO EM UM COLÉGIO TÉCNICO
}

\author{
Rubia Cristina Wegner \\ Universidade Federal Rural do Rio de Janeiro \\ rubicawegner@gmail.com \\ Marcelo Pereira Fernandes \\ Universidade Federal Rural do Rio de Janeiro \\ mapefern@gmail.com \\ Guilherme Cabral Pisno \\ Universidade Federal Rural do Rio de Janeiro \\ guilherme.pisno@hotmail.com
}

Utanaan Reis Barbosa Filho Universidade Federal Rural do Rio de Janeiro utanaan.reis@gmail.com

Natalia de Frias Simões Paes Universidade Federal Rural do Rio de Janeiro nataliafspaes@hotmail.com

Luiz Fernando Rodrigues de Oliveira Universidade Federal Rural do Rio de Janeiro lfro97p@gmail.com

\section{Resumo}

Este texto apresenta a concepção e o desenvolvimento de uma atividade de extensão realizada por alunos de Ciências Econômicas da UFRRJ no colégio técnico dessa Universidade, sem fins lucrativos, para atender alunos do ensino médio e ensino médio técnico. Entre os anos de 2018 e 2019, professores e discentes do curso desenvolveram um projeto de extensão junto aos estudantes de ensino médio e técnico do CTUR, buscando interação dialógica em temas de teoria econômica. O objetivo foi abordar, em aulas-encontros conduzidas por estudantes do curso de Ciências Econômicas, temas abrangentes que permeiam a vida socioeconômica da sociedade brasileira e cuja explicação parte do conhecimento da teoria econômica. Os temas foram divididos entre os estudantes-membro, somando ao todo nove temas: Microeconomia, Macroeconomia, História do Pensamento Econômico, Mercado de Trabalho, Desenvolvimento Econômico e Distribuição de Renda, Desenvolvimento Regional, Economia Monetária e Matemática Financeira. Também foi realizada uma aula inaugural para apresentar o curso de Ciências Econômicas da UFRRJ, as áreas de atuação do economista, o mestrado em Economia Regional e Desenvolvimento, bem como o tema de cada uma das aulas-encontro. Enquanto os estudantes do CTUR aprofundaram suas capacidades de argumentação e reflexão crítica nos temas trabalhados dialogicamente, os estudantes da graduação aprimoraram essas capacidades, incluindo a didática.

Palavras-Chave: Projeto de Extensão; Ensino de Economia; Colégio Técnico; Popularização da Ciência.

\section{ECONOMY GOES TO SCHOOL: EXTENSION REPORTS IN A TECHNICAL COLLEGE}

\begin{abstract}
This text presents the conception and development of an extension activity carried out by students of Economics Sciences of UFRRJ in the technical college of this University, non-profit to serve high school and technical high school students. Between the years 2018 and 2019, professors and students of the course developed, therefore, an extension project with high school and technical high school students of CTUR, seeking dialogical interaction on topics of economic theory. The goal was to address, in class-meetings conducted by students of the Economic Sciences course, broad themes that permeate the socioeconomic life of Brazilian society and whose explanation departs from the knowledge of economic theory. The topics were divided among the student-members, adding up to a total of nine themes: Microeconomics, Macroeconomics, History of Economic Thought, Labor Market, Economic Development and Income Distribution, Regional Development, Monetary Economics, and Financial Mathematics. An inaugural class was also held to introduce the Economics course at UFRRJ, the economist's areas of expertise, the Master's in Regional Economics and Development, as well as the theme of each of the meeting classes. While the CTUR students deepened their argumentation and critical reflection skills on the themes worked on dialogically, the undergraduate students improved these skills, including didactics.

Keywords: Extension Project; Economics Classes; Technical College; Science Popularization.
\end{abstract}




\title{
LA ECONOMIA HACIA LA ESCUELA: INFORMES DE EXTENSIÓN EN UM COLÉGIO TECNICO
}

\begin{abstract}
Resumen
Este texto presenta la concepción y el desarrollo de una actividad de extensión realizada por los estudiantes de Ciencias Económicas de la UFRRJ en la escuela técnica de esta Universidad, sin fines de lucro para atender a los estudiantes de la escuela secundaria y de la escuela técnica. Entre los años 2018 y 2019, los profesores y alumnos del curso desarrollaron, por lo tanto, un proyecto de extensión con los alumnos de secundaria y bachillerato técnico del CTUR, buscando la interacción dialógica en temas de teoría económica. El objetivo era abordar, en los encuentros de clase realizados por los alumnos del curso de Ciencias Económicas, amplios temas que impregnan la vida socioeconómica de la sociedad brasileña y cuya explicación parte del conocimiento de la teoría económica. Los temas se repartieron entre los estudiantes-miembros, sumando un total de nueve temas: microeconomía, macroeconomía, historia del pensamiento económico, mercado de trabajo, desarrollo económico y distribución de la renta, desarrollo regional, economía monetaria y matemáticas financieras. También se realizó una clase inaugural para presentar el curso de Ciencias Económicas en la UFRRJ, las áreas en las que trabajan los economistas, la Maestría en Economía Regional y Desarrollo, así como el tema de cada uno de los encuentrosclases. Mientras que los estudiantes del CTUR profundizaron en su capacidad de argumentación y reflexión crítica sobre los temas trabajados dialógicamente, los estudiantes de grado mejoraron estas capacidades, incluyendo la didáctica.
\end{abstract}

Palabras Clave: Proyecto de Extensión; Enseñanza de la Economía; Colegio Técnico; Divulgación Científica. 
Economia vai à escola: relatos de extensão em um colégio técnico

\section{INTRODUÇÃO}

A articulação entre discentes, docentes e técnicos, no âmbito de uma instituição de ensino superior público em seus níveis de graduação, pós-graduação e ensino médio e técnico (quando houver) traduz a indissociabilidade entre ensino, pesquisa e extensão. E as atividades próprias da extensão universitária podem representar a sua articulação, promovendo formação, progresso do conhecimento e interação e troca de saberes com a comunidade externa. A Universidade Federal Rural do Rio de Janeiro (UFRRJ) está sediada no estado do Rio de Janeiro e tem sua origem na Escola Superior de Agricultura Medicina Veterinária (ESAMV), que foi criada no início do século XX, em 1910, por meio de decreto presidencial na época. Em 1943, passou a ser Universidade Rural; em 1960, Universidade do Rio de Janeiro; em 1962 passou a ser chamada de Universidade Rural do Rio de Janeiro, e, em 1967, foi transferida do Ministério da Agricultura para o Ministério da Educação e passou a ser Universidade Federal Rural do Rio de Janeiro. (UFRRJ, 2013)

O Colégio Técnico da UFRRJ foi criado em 1973, a partir da fusão do Colégio Técnico de Economia Doméstica (CTED) e Colégio Técnico Agrícola Ildefonso Simões Lopes. Contudo, a rigor, o Colégio Técnico da Universidade Federal Rural do Rio de Janeiro (CTUR) começou a sua jornada em 1943, com o Aprendizado Agrícola (AA), então subordinado à Superintendência do Ensino Agrícola e Veterinário no Ministério Agrícola. Até 1969, havia outras duas instituições de ensino médio na Universidade - Colégio Universitário e Colégio Técnico em Economia Doméstica (CTED). Com a Reforma Universitária de 1968, surgiu o CTUR, constituído de cursos profissionalizantes de nível médio e se mantendo vinculado à UFRRJ. Desde 2008, pertence à Rede Federal de Educação Profissional Científica e Tecnológica. De acordo com Relatório de Gestão da UFRRJ, em 2018, o CTUR possuía 1 mil alunos em 4 cursos técnicos e um curso de ensino médio.

A extensão é um dos pilares essenciais da UFRRJ. Em seu documento Plano de Desenvolvimento Institucional, PDI (2018-2022), dentre seus objetivos estratégicos estão, além de fomentar a participação docente, discente e de técnicos em ações de extensão, ampliar ações de integração de extensão com ensino e pesquisa, desenvolver projetos de extensão voltados para a comunidade no entorno dos campi e integrar ações entre a Universidade e CTUR (UFRRJ, 2017).

O projeto de extensão Economia no CTUR, objeto deste texto, originou-se na busca da coordenação do curso de graduação em Ciências Econômicas por uma integração com a comunidade de Seropédica e de uma articulação com alunos do CTUR nos conteúdos tratados nas disciplinas do curso. Assim, com o intuito de aprimorar e estender os projetos de extensão no curso de Ciências Econômicas na UFRRJ, em uma reunião do fórum discente do curso, debateu-se a necessidade de aproximar o curso da cidade de Seropédica. Dentre as ações, pensou-se em 
Economia vai à escola: relatos de extensão em um colégio técnico

promover feiras de profissões nas escolas e, se possível, ministrar conceitos básicos de Economia que norteiam os grandes veículos de comunicação. Iniciou-se um esforço de levar a ideia para o CTUR como projeto piloto e, com isso, avaliar a experiência. A diretoria do Colégio concordou em participar e formalizou convite para participar da Semana Acadêmica, na qual foram apresentados o projeto e assuntos relacionados à economia do dia a dia.

Este projeto se desenvolveu em um primeiro momento - durante o segundo semestre de 2018 - e em um segundo momento - ao longo do ano de 2019 - e, em ambos, consistiu em aulasencontro com estudantes do ensino técnico do CTUR, em uma sala de aula localizada em seu prédio principal. Foram selecionados estudantes da graduação em Ciências Econômicas como estudantes membros, isto é, aqueles que foram responsáveis pela elaboração dos materiais das aulas encontros e por sua condução. Para definição dos estudantes integrantes do CTUR, orientadores do projeto e os estudantes membros acordaram em conjunto com a coordenação pedagógica da instituição, que se mostrou receptiva desde a primeira aproximação realizada pelos professores coordenadores do projeto e alunos membros. Definiu-se, em conjunto, para o primeiro momento, que se destinaria aos estudantes dos cursos técnicos - agroecologia e hotelaria - que desejassem participar. No segundo momento, em função de mudanças estruturais e institucionais, o públicoalvo foi definido pelo horário disponível dos alunos participantes.

Este relato se volta para descrever a organização adotada pela equipe de alunos de graduação e coordenadores do projeto de extensão "Economia no CTUR", para a elaboração e a sua implementação, bem como os aspectos observados e sistematizados durante a sua execução. Espera-se que a partir da descrição e avaliação desta experiência se possa contribuir com a realização de novos projetos de extensão. Além desta introdução, o texto se constitui de uma seção que contextualiza o projeto, a descrição do processo de elaboração das aulas-encontro, a apresentação dos resultados da ação extensionista e as considerações finais.

\section{EXTENSÃO E ENSINO: PROJETO ECONOMIA NO CTUR}

A educação financeira é um dos temas incorporados na Base Nacional Curricular Comum (BNCC), a qual recomenda que, dentro da autonomia e das competências das escolas, a inserção de abordagens de temas 'contemporâneos' que afetam o contexto local, regional e nacional dos estudantes. O parecer CNE/CEB n. 11/2010 e a Resolução CNE/CEB n. 7/2010 recomendam que, associado à educação financeira, abordem-se temas como saúde, vida familiar e social, educação para o consumo, educação para o trabalho, ciência e tecnologia, bem como diversidade 
Economia vai à escola: relatos de extensão em um colégio técnico

cultural (BRASIL, 2010a). Após a crise financeira internacional de 2008, tornaram-se frequentes recomendações do ensino de educação financeira nas escolas, por instituições do mercado financeiro. A Organização para a Cooperação e Desenvolvimento Econômico (OCDE) recomendava, já em 2003, que se promovesse a educação financeira desde os primeiros anos da educação escolar formal (OCDE, 2015). No Brasil, em 2010, o Decreto Federal 7.397 criou a Estratégia Nacional de Educação Financeira (ENEF), uma mobilização multissetorial com o objetivo de promover ações de educação financeira no país (BRASIL, 2010b). A sua criação foi conduzida por nove órgãos e entidades governamentais e quatro organizações da sociedade civil, que integram o Comitê Nacional de Educação Financeira (CONEF). Todos os programas da ENEF se guiam por um plano diretor e suas ações são conduzidas por meio de programas transversais e setoriais e, de acordo com informações do site do CONEF, sua atuação ocorre a partir da realização de conferências sobre o tema, visando à inclusão da educação financeira nas escolas.

Em função da BNCC e da discussão gerada sobre a reforma do ensino médio, nos últimos anos os projetos de interação entre cursos de graduação em Ciências Econômicas com as escolas - ensino fundamental e/ou médio - têm crescido, no Brasil. Por outro lado, a percepção de que a compreensão de aspectos econômicos essenciais escapa da maior parte da população tem motivado a conexão entre essas esferas do ensino; constituindo essa interação, assim, uma forma de ampliar a educação cidadã dos alunos de ensino médio e desmistificar a falsa ideia de que a Economia é uma ciência inacessível. É crescente, ainda, o número de economistas que se preocupam em facilitar a compreensão da economia, como os livros que têm sido publicados recentemente. Entre eles podemos citar o Economia: modo de usar. Um guia básico dos principais conceitos econômicos, de Ha-Joon Chang, de 2015. Em 2018, o Conselho Federal de Economia (COFECON) lançou o Desafio quero ser economista, para os estudantes do ensino médio. Seu objetivo é apresentar os conceitos econômicos essenciais da Economia, bem como o mercado de trabalho do profissional economista. O CTUR, colégio técnico da UFRRJ, oferece cursos de ensino médio e cursos técnicos, possibilitando essa interação entre alunos graduandos e alunos do ensino básico.

A Economia é parte da vida quotidiana das pessoas - mesmo que elas não percebam ou percebam apenas o seu aspecto monetário e financeiro. Decisões tomadas por autoridades governantes, técnicos-burocratas, legisladores - são em grande parte motivadas por questões econômicas. Questões que são tratadas nas diferentes escolas que compõem a Ciência Econômica e, normalmente, fonte de controvérsias. Um exemplo recente é a Emenda Constitucional 95 (conhecida por "Teto dos Gastos"), promulgada em dezembro de 2016. Sua proposta de congelar 
Economia vai à escola: relatos de extensão em um colégio técnico

os gastos em saúde e educação por 20 anos afetará a vida da sociedade brasileira enquanto sua elaboração e aprovação se deram por uma motivação econômica muito polêmica: a contenção de gastos públicos com vistas ao equilíbrio macroeconômico. Um leigo em Economia normalmente acataria essa explicação, corrente nos principais meios de comunicação, uma vez que a própria palavra equilíbrio parece ter um significado positivo. Um estudante de Economia, em geral, tem conhecimento que o permitiria ir além; ele teria mais condições de criticar a decisão pelo Teto dos Gastos e questionar os marcos teóricos que o sustentam. Logo, elucidar a Economia aos alunos do ensino médio representa elucidar também sua capacidade crítica, sua capacidade de exercício da cidadania, ainda que ele venha a ter contato apenas com uma parte de todo o conhecimento que ele teria se fosse estudante de Economia.

Por outro lado, disseminar - e dessa forma, facilitar - o conhecimento de Economia entre alunos de ensino médio, sobretudo da rede pública, é, no Brasil, ainda uma novidade. Nos Estados Unidos, por exemplo, essa interação é discutida e realizada desde a década de 1970, de modo que conteúdos de Economia transversalizam disciplinas de Matemática e Estudos Sociais em 26\% dos estados norte-americanos (BATISTA; SILVA, 2010). Em um país em desenvolvimento, com reduzida inserção da população em atividades financeiras, não surpreende que Economia não pertença, nem mesmo transversalmente, aos conteúdos de disciplinas obrigatórias do ensino médio.

Existem também projetos recentes de órgãos como a Comissão de Valores Mobiliários (CVM) de formação dos brasileiros em conceitos relacionados, principalmente, ao mercado financeiro e de capitais, via o "Portal do Investidor". Perobelli et al. (2018) citam outras iniciativas levadas a cabo por instituições privadas, como: Associação Nacional dos Bancos de Investimento, Bolsa de Valores de São Paulo e Fundação Bradesco. Como os próprios autores ressaltam, essas iniciativas são voltadas para os seus clientes de modo a convencê-los de que essas instituições oferecem as melhores soluções financeiras. A percepção de que o curso de Economia tenha considerável aderência a uma formação cidadã, e ao mesmo tempo em que a academia é levada às escolas, tem estimulado iniciativas em mais universidades públicas. A Faculdade de Economia e Administração da Universidade de São Paulo (USP) mantém há aproximadamente oito anos o projeto "Econoteen", que tem por objetivo "criar canais de comunicação com a sociedade e diminuir distância entre o ensino de Economia e as pessoas que constroem e vivenciam a Economia em si." (USP, 2014).

Ainda que não se possa negar que a educação financeira estimule estudantes de ensino médio a compreender os possíveis efeitos da forma como eles gastam seu dinheiro, bem como das 
Economia vai à escola: relatos de extensão em um colégio técnico

possibilidades de aumentar sua "poupança", deve-se destacar que a promoção da expansão do conhecimento em Economia é possível de ser mais aprofundada. A formação cidadã de pessoas com idades entre 15 e 18 anos - prestes a se tornarem adultos - deve compreender assuntos (ou objetos) que lhes permitam ir além do senso comum; que lhes permitam exercer sua cidadania. Adultos meros reprodutores de falas pré-concebidas da Ciência Econômica - em assuntos sobre inflação, gasto público e de fatores do crescimento - conformam praticamente uma lei geral. Romper com esse ciclo representa o ensino dialógico de diferentes abordagens da teoria econômica para os mesmos fenômenos, assuntos, objetos. Neste projeto, buscou-se que não somente os alunos participantes, mas também os alunos membros tivessem oportunidade de aprendizagem não-doutrinária, apenas, de Economia.

$\mathrm{Na}$ fase da elaboração das ações no âmbito do projeto, a premissa considerada foi a de que se tratava do primeiro contato com os estudantes do ensino médio. Nesse sentido, se optou por debater conjuntura econômica do século XXI no Brasil, mais especificamente. O tema apresentado foram os governos Lula e Dilma, finalizando com a PEC dos gastos públicos. Esta apresentação foi crucial para que conseguíssemos enxergar o interesse dos alunos no assunto, assim como definir como abordar apresentações que fujam do padrão universitário acadêmico, podendo esclarecer dúvidas e alcançar debates que permeiam a simplicidade do contato e da informação econômica.

O projeto foi executado em dois momentos. O primeiro, no segundo semestre de 2018, quando a ideia foi apresentada à direção do CTUR e aos alunos, na Semana Acadêmica do Colégio Técnico. Os encontros começaram, no mesmo semestre, e foram estruturados em 04 temas (encontros), a saber: inflação, emprego, crescimento, gasto público e desenvolvimento econômico. Esse primeiro momento foi fundamental, pois se tornou um incentivo para a preparação dos materiais e para o grupo identificar os assuntos que seriam mais relevantes para serem apresentados em aula. O segundo momento, a partir do primeiro semestre de 2019, em que o projeto passou a contar com apoio institucional por meio de uma bolsa de extensão (BIEXT/UFRRJ). Dada a experiência acumulada em 2018, adotaram-se alguns parâmetros para a realização das atividades: definição de alunos membros - alunos da graduação que conduziriam as aulas/encontros - de alunos participantes, os alunos do CTUR. Os professores coordenadores do projeto atuariam na fase de decisão e de planejamento dos conteúdos e de elaboração dos materiais didáticos.

Para este segundo momento, definiu-se também uma metodologia básica para o andamento das atividades do projeto, que consiste em: definição em conjunto dos temas, elaboração dos pontos que serão tratados, elaboração do material didático e aplicação (aula). 
Economia vai à escola: relatos de extensão em um colégio técnico

\section{DESCRIÇÃO DO PROCESSO DE ELABORAÇÃO DAS AULAS-ENCONTRO}

Nesta subseção descreve-se o processo adotado pela equipe - docentes coordenadores de projeto e estudantes-membro - para elaboração das aulas-encontro, no segundo momento da condução do projeto. A organização adotada consistiu em fases e ações voltadas para a sistematização dos conteúdos de cada aula-encontro a ser conduzida por estudantes-membros, de modo a permitir a melhor compreensão de termos e conceitos da teoria econômica por estudantesintegrantes do projeto. Esse formato de elaboração foi construído dialogicamente na equipe, considerando a experiência dos professores coordenadores, bem como nos relatos de Perobelli et al. (2013).

A primeira reunião do grupo aconteceu em janeiro de 2019, sem se ter certeza da turma que constituiria os alunos participantes. Nas reuniões de planejamento a dinâmica das aulas foi debatida, isto é, discutiu-se como executar o material didático, os temas e seu encadeamento lógico. Para isso, os assuntos foram divididos entre os integrantes, somando nove temas: Microeconomia, Macroeconomia, História do Pensamento Econômico, Mercado de Trabalho, Desenvolvimento Econômico e Distribuição de Renda, Desenvolvimento Regional, Economia Monetária e Matemática Financeira. Além disso, se optou por acrescentar uma aula inaugural para apresentar o curso de Ciências Econômicas da UFRRJ, as áreas de atuação do economista, o mestrado, bem como a apresentação e o tema das aulas.

Coletivamente foi acordado em abordar as seguintes questões: Escolas de pensamento econômico, evidenciando que esta ciência é permeada por diversas visões que são em grande parte conflitantes; conceitos básicos de Macroeconomia, seu surgimento e seus avanços para o curso; conceitos básicos de Microeconomia, tentando explicitar o funcionamento das firmas/empresas e o comportamento dos consumidores, dada determinadas características do mercado; mercado de trabalho, à guisa do momento em que o país vive (desemprego elevado, subemprego e nova morfologia do trabalho); desenvolvimento econômico, mostrando as características empreendidas no caso brasileiro, além das especificidades do desenvolvimento do Rio de Janeiro e seus polos de crescimento; desenvolvimento regional na tentativa de aproximar o debate da realidade de Seropédica; Economia Monetária, tentando explicar o funcionamento do sistema bancário, liquidez na economia e a operacionalidade da política monetária; e por fim, Matemática Financeira, considerando o grande endividamento das famílias brasileiras.

Tendo em vista a disponibilidade de uma tarde semanal pelos estudantes do CTUR, acordamos cinco aulas a partir das questões explicitadas acima. 
Economia vai à escola: relatos de extensão em um colégio técnico

O primeiro tema deveria não somente introduzir o que é a Economia e partir de suas noções mais básicas, como também levar os alunos participantes a compreender que a Ciência Econômica tem escopo maior do aquele que é apresentado rotineiramente pelos principais meios de comunicação. Assim, foi apresentada uma breve perspectiva histórica da Economia, tendo como base uma matéria específica das disciplinas de Economia Política I e História do Pensamento Econômico, além de suas divisões mais básicas entre microeconomia e macroeconomia, os dois grandes pilares do curso. O material didático foi elaborado trazendo conceitos elementares de microeconomia - teoria do consumidor e da produção -, de macroeconomia - básico de Contas Nacionais, de modelo keynesiano básico e se acordou tratar de conceitos com um nível maior de abstração, como neutralidade da moeda.

A construção da segunda aula-encontro teve por diretriz lançar explicações teóricas de Economia Regional e Urbana à realidade da Baixada Fluminense, sobretudo, do município de Seropédica. O tema da aula foi desenvolvimento regional e os conceitos definidos para discussão com os alunos participantes foram: concentração regional, desconcentração regional, industrialização e desindustrialização e polos regionais de desenvolvimento. Ademais, construiu-se um histórico do desenvolvimento econômico da região, com destaque para fatos da última década.

Coordenadores do projeto e alunos membros entenderam que o terceiro tema poderia ter tratamento mais profundo, podendo suscitar um debate entre os alunos. Então se decidiu abordar a temática do mercado de trabalho no terceiro encontro, e a situação de desemprego no país, que, além de ser algo de interesse geral entre alunos de ensino médio e superior, é matéria de controvérsias teóricas e interpretativas entre os economistas. Foram acordados os seguintes tópicos a serem tratados: conceito de mercado de trabalho conforme as pesquisas do Instituto Brasileiro de Geografia e Estatística (IBGE), incluindo-se conceitos de emprego, desemprego, e explicações do fenômeno desemprego. A Figura 1 se refere ao material didático sobre mercado de trabalho utilizado de referência para os estudantes-membro. 
Figura 1: Material didático da aula 3: mercado de trabalho

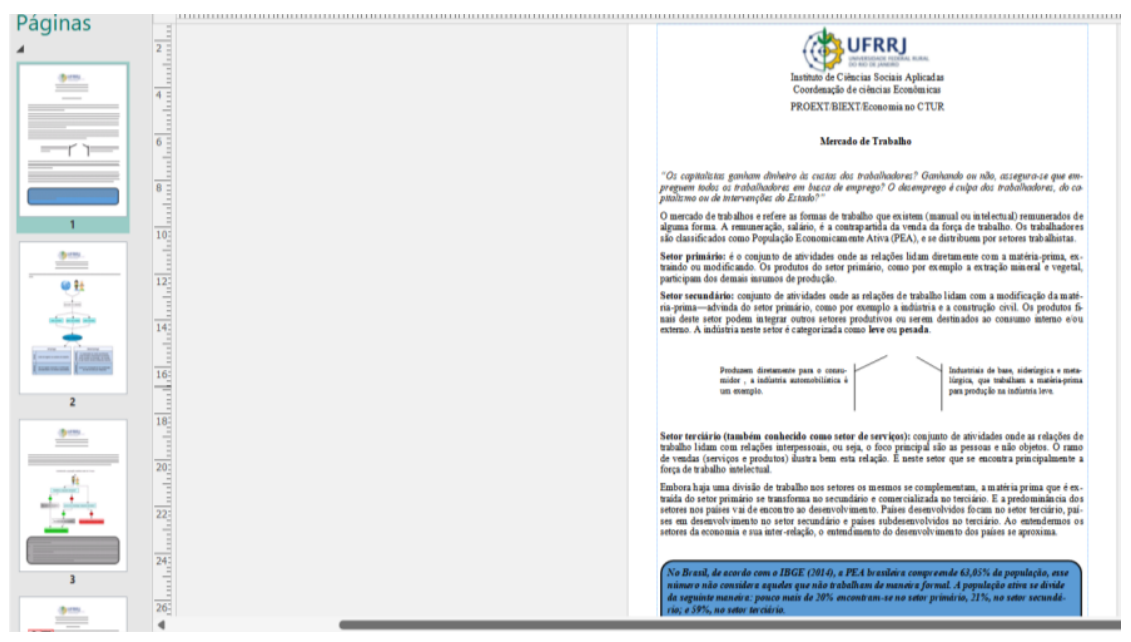

Fonte: Acervo do projeto

Com a preocupação de abordar um tema de teoria econômica que trouxesse esclarecimentos sobre um assunto debatido naquele momento, o quarto tema escolhido entre alunos-membros e coordenadores do projeto foi o da experiência do Brasil com o processo de privatização das estatais a partir da década de 1990, enfatizando principalmente os anos do governo Michel Temer (2016-2018). Com essa aula-encontro, intencionava-se apresentar elementos teóricos do debate sobre "por que privatizar?" e "privatização é necessária para promover o crescimento econômico de um país?".

Por fim, para quinta aula, foi definido trazer noções sobre administração financeira, vide o considerável nível de endividamento e inadimplência no país, somando-se a uma breve introdução complementar sobre economia monetária. Esta é outra grande área de estudo da economia, ligado ao funcionamento do sistema bancário presente em nosso cotidiano, mas que parece algo muito distante da compreensão de boa parte da população brasileira. Discutiu-se que a elaboração do material didático traria conceitos elementares sobre economia monetária, funções das instituições financeiras nacionais - com destaque para diferença entre Banco Central e bancos comerciais - e noções sobre a formação de taxas de juros, estendendo-se para conceituação de juros simples e compostos tratados com ampliação da percepção pelos alunos de como aspectos mais amplos, tratados na teoria econômica, podem afetar suas finanças.

$\mathrm{Na}$ sequência se procedeu à distribuição das atividades entre os coordenadores do projeto e os alunos membros. Houve consenso de que seria melhor ter dois alunos-membros por aula, para que ninguém se sobrecarregasse em uma primeira experiência de ensino. Para uma melhor organização das aulas, e para despertar um maior interesse nos alunos do CTUR, se começou a 
Economia vai à escola: relatos de extensão em um colégio técnico

desenvolver um material didático sobre os temas escolhidos e sob a orientação dos professores do curso participantes do projeto.

Em seguida, o esforço foi de elaborar os materiais didáticos, com a preocupação de tornálos acessíveis - com uma linguagem simples aos estudantes de ensino médio - mas sem perder o rigor teórico, interativo com o uso de imagens e balões explicativos e, ao final, exercícios para testar o entendimento dos alunos e facilitar a aproximação deles. Houve o cuidado de pedir para que os alunos participantes lessem o material e dessem um retorno quanto ao grau de entendimento oferecido pelo texto, bem como se o número de páginas dava conta do que se estabeleceu nos objetivos em termos de conteúdo, de exercícios e sugestão de obras de referência. O retorno dos estudantes-integrante foi favorável. O CTUR disponibilizou uma turma de primeiro ano para o projeto, e isso nos indicou que a linguagem utilizada deveria ser aquela mais simples possível, por se tratar de alunos que acabaram de sair do ensino fundamental.

\section{RESULTADOS E ANÁLISES}

Nesta seção, o objetivo é analisar o processo de implementação e execução do projeto. Também se define alguns pontos teóricos que permitam, a partir da prática extensionista realizada, se chegar a observações sistematizáveis ou generalizantes.

Ao longo do segundo semestre de 2018, quando foi iniciada a primeira edição do projeto, constatou-se resultado positivo dos alunos quanto aos conteúdos abordados. Podem ser destacadas algumas características dessa edição em relação ao proposito principal do projeto: tornar a linguagem econômica mais simples, explicando o "economês" com exemplos próximos à realidade do aluno.

Apesar de serem alunos de primeiro ano do ensino médio, eles se mostraram atentos ao momento em que o país vivenciava, sendo capazes de interligar os conceitos de economia que estavam sendo trabalhados com uma determinada política econômica praticada pelo governo; segundo, a quantidade de questionamentos manteve as aulas com debates constantes. Com isso os alunos-membros decidirem reduzir o conteúdo programático por aula para que os estudantes pudessem se expressar o máximo possível, e; terceiro, perceberam também que os alunos participantes eram capazes de estabelecer conexões entre o conteúdo das disciplinas obrigatórias de seu curso - como, por exemplo, História, a qual um aluno indagou sobre a planificação 
Economia vai à escola: relatos de extensão em um colégio técnico

econômica da ex-União Soviética (URSS) e os elementos que constituem a China como uma das potencias globais.

Esse primeiro momento foi essencial para a elaboração do segundo momento no primeiro semestre de 2019 do projeto, com os cinco encontros-aula descritos na subseção anterior. Entendeu-se que era fundamental preparar o material didático e se pensar em tópicos mais amplos. Não se encontraram exemplos desse exercício na literatura, isto é, de projetos de extensão de natureza similar, em que os alunos membros tenham se proposto a construir material didático para disponibilizar ao público-alvo do projeto.

Por outro lado, um método dialógico para montagem das aulas-encontro pela equipe é descrito por Baron et al. (2020), que buscaram a interação entre estudantes universitários e da educação básica de forma a responder em conjunto questionamentos oriundos das conversas e apresentações iniciais de grandes temas. Em projetos que envolvem interação entre estudantes de diferentes níveis e em projetos da área de educação, acumular experiência de uma edição inicial neste artigo denominada de primeiro momento - para uma segunda edição aprimorada é primordial. Falcão e Caldas (2018) descrevem ter seguido esse mesmo procedimento e ressaltam: "Os procedimentos metodológicos privilegiaram o diálogo, compreendendo os estudantes enquanto sujeitos do processo educativo" (p.152). É uma forma, portanto, de aprimorar os mecanismos de diálogo e de interação que levem à construção coerente e mais compreensível dos conceitos a serem abordados. Moura Júnior et al. (2020) discorrem sobre um projeto de extensão voltado para melhorar o aprendizado de Ciências Exatas entre jovens em situação de vulnerabilidade socioeconômica. Uma proposta como essa, conforme os autores avaliam no artigo, é uma forma também de incidir mais diretamente sobre o aprendizado dos alunos do ensino básico quanto ao currículo escolar. Desta forma, os contratempos com impossibilidades dos alunos em períodos de avaliação seriam reduzidos, dado o seu interesse direto.

As aulas-encontro transcorreram dentro do planejado quanto ao cronograma, à divisão do trabalho entre os estudantes-membro e às metas previstas. Ao longo das aulas, os estudantesmembro foram destacando que os estudantes integrantes mantiveram uma postura questionadora, respeitosa e interessada. Mostraram-se capazes de resolver os exercícios propostos em cada material didático e de formular avaliações reflexivas e críticas a partir do conteúdo apresentado. $\mathrm{Na}$ Figura 2, a estudante-membro interage com os estudantes integrantes, apresentando uma formulação teórica essencial da teoria econômica, o modelo "IS-LM", na primeira aula-encontro. 
Figura 2: Participantes do projeto ministrando na aula.

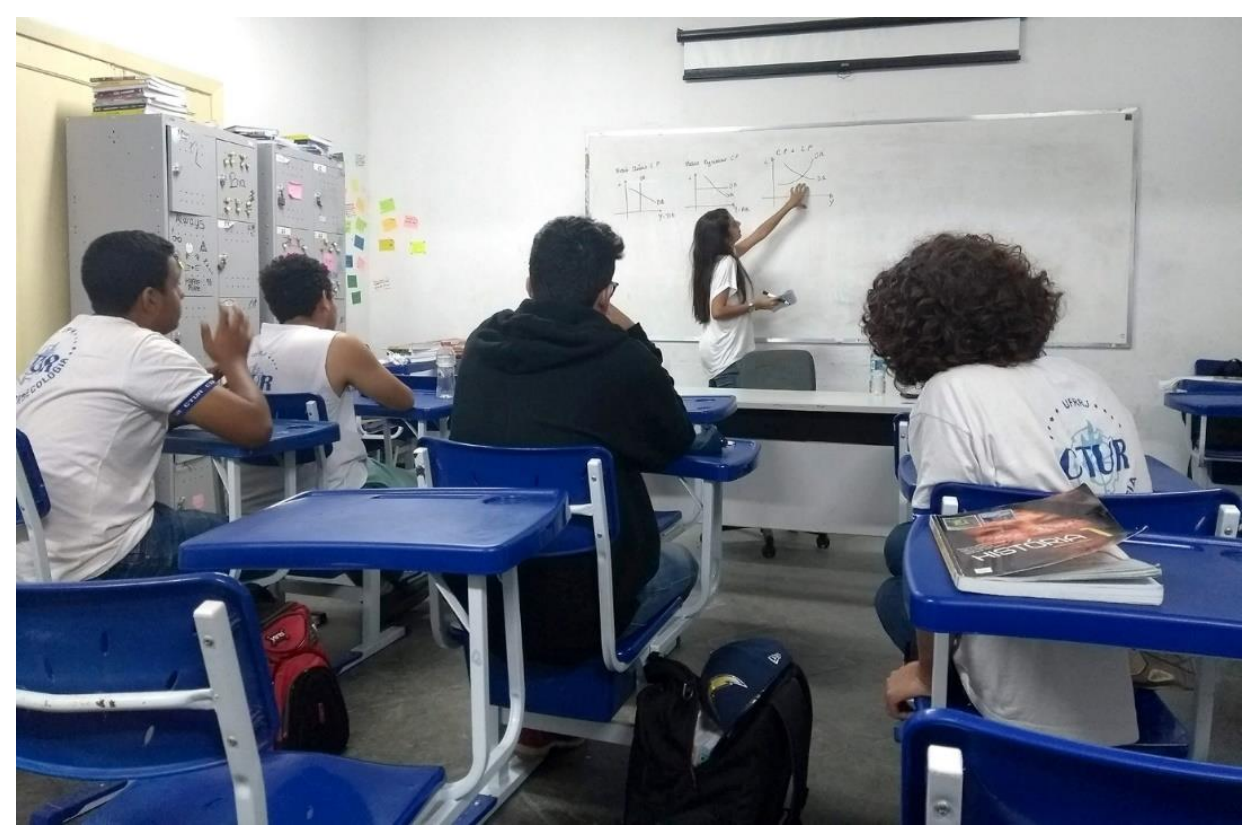

Fonte: Acervo do projeto

Quanto ao segundo momento, as primeiras aulas-encontro foram momentos muito produtivos, pois se conseguiu expor as afinidades teóricas da equipe e adequar às dinâmicas das aulas.

Nesse segundo momento, os alunos-membro que haviam participado da primeira edição ou primeiro momento contribuíram não somente com a sistematização dos conteúdos, mas com a própria organização das aulas-encontro. A preocupação com o equilíbrio entre uma linguagem acessível e a preservação da qualidade e do conteúdo técnico provenientes da economia sempre permearam a elaboração do material.

Do ponto de vista do estudantes-membro, conforme as reuniões de avaliação e de preparação das aulas-encontro se sucediam, seus relatos indicavam que, mesmo com um número de estudantes-integrantes menor do que o esperado, a interação dialógica foi de elevado nível, estando os materiais didáticos e o formato das aulas-encontro, bem como os temas selecionados em consonância com suas indagações à época da execução do projeto.

As experiências na literatura de projetos similares - Perobelli et al. (2018), outros citados acima -, em curso de graduação em Economia, restringem-se à educação financeira. Sem dúvida, trata-se de uma interação formativa de forte impacto, na medida em que se elucidam conceitos quotidianos - como juros, inflação, transações bancárias e financeiras -, apontando-se algumas de suas relações de causa e efeito ou como esses conceitos interagem entre si. No projeto de extensão 
Economia vai à escola: relatos de extensão em um colégio técnico

"Economia no CTUR", amplia-se essa compreensão, isto é, a construção de argumentos para apresentação e diálogo com alunos do ensino médio sobre Economia, levando-os a compreender, por exemplo, que não se trata de um aprendizado puramente técnico.

Neste projeto, o esforço tem sido construir de uma forma sistematizada, incluindo-se até mesmo material didático, os pontos teóricos de tratamento de questões econômicas vivenciadas pelos alunos participantes. Buscou-se organizar as aulas-encontro na forma de temas e de tópicos a serem apresentados e dialogados. Enquanto as aulas-encontro foram sendo precedidas de reuniões para levantamento de organização e sistematização de cada tema, os estudantes-membro encontraram mais um momento para pensar o "ensinar" ou "lecionar" e para fortalecer apropriação dos conceitos e teorias da ciência econômica.

Conclusões gerais que foram construídas no âmbito da realização deste projeto: o apoio institucional da escola ou colégio técnico, como foi neste projeto, é determinante para sua boa execução; dividir a elaboração das aulas-encontro em três fases: definição dos temas que serão tratados - sempre tomando por partida a realidade mais recente vivenciada e seu cotejamento com a teoria econômica -; definição dos materiais básicos para estudo e preparação das aulas-encontros e do material didático e reuniões de discussão dos conceitos básicos e suas conexões com a realidade, assim como o planejamento das aulas-encontro. Esse processo é uma forma de um exercício teoria-prática que fortalece a interação entre ensino e extensão. O aprendizado dos alunos-membro se reforça em função da preparação para o projeto de extensão. Dessa forma, torna-se mais orgânica a aula-encontro, da qual se espera revelar aos alunos participantes, neste caso do ensino médio, compreender a articulação entre teoria e prática no seu processo de tomada de consciência da realidade econômica que os circundam.

Por fim, ainda no mês de dezembro de 2019, a equipe foi até o Centro Integrado de Educação Pública (CIEP), também localizado no município de Seropédica, para apresentar o projeto de extensão e convidar os estudantes, a partir do primeiro ano do ensino médio, a participar do projeto. Distribuíram-se folhetos explicativos e uma conversa foi realizada com uma turma de aproximadamente 40 estudantes. Os docentes orientadores acordaram com diretor e coordenadora pedagógica os passos seguintes a serem tomados em 2021, incluindo procedimentos quanto à inscrição e divulgação. Com a deflagração da pandemia do novo coronavírus, adaptações foram realizadas e o projeto transcorreu no CIEP, de forma remota e com uma nova equipe, uma vez que os discentes que participaram do projeto "Economia no CTUR", em sua maioria, colaram grau. 
Economia vai à escola: relatos de extensão em um colégio técnico

\section{CONSIDERAÇÕES FINAIS}

Este relato teve por objetivo descrever a organização adotada pela equipe de alunos de graduação e coordenadores do projeto de extensão "Economia no CTUR" para a elaboração e sua implementação, bem como os aspectos observados e sistematizados durante a sua execução. Sua elaboração envolveu toda a equipe do projeto de extensão, incrementando entre os alunos de graduação sua habilidade de escrita e de elaboração de textos científicos. Ao se elaborar seções deste relato, como metodologia, por exemplo, visualizaram-se as conexões entre extensão e pesquisa. Um relato como esse terá o valor e o significado de um registro de todo o trabalho desenvolvido neste que foi o primeiro projeto de extensão envolvendo o curso de graduação em Ciências Econômicas e o CTUR.

Dentre as conclusões principais, estão: cronogramas para projetos de extensão em escolas ou colégios técnicos devem ser elaborados considerando o período de avaliação desses estudantes, de forma estrita, ao ser transposto para uma forma mais dialógica e mais direta, os conteúdos de Economia estimulam a curiosidade dos alunos de ensino médio e técnico, levando-os a construir as esperadas interações entre os conceitos e seu dia a dia, um bom planejamento das aulas (aulasencontro como denominamos no projeto) permite maior segurança de condução pelos alunos membros e permite que percebam e induzam bons momentos de participação dos alunos participantes e a elaboração de material didático é um esforço válido tanto para documentar os conteúdos abordados quanto para facilitar sua compreensão pelos alunos participantes. A dedicação da equipe é essencial, da mesma forma, projetos neste formato tendem a promover a interação entre graduação e ensino médio. Muitos alunos participantes se sentiram atraídos e interessados a cursar Ciências Econômicas e até mesmo se sentiram mais envolvidos na Universidade de modo geral.

\section{AGRADECIMENTOS}

Ao Colégio Técnico da Universidade Federal Rural do Rio de Janeiro (CTUR/UFRRJ), que viabilizou a execução do projeto acolhendo a equipe em sua estrutura disponibilizando espaço, tempo e discentes.

À Pró-Reitoria de Extensão da Universidade Federal Rural do Rio de Janeiro (UFRRJ) pelo apoio na execução do projeto "Economia no CTUR" e no financiamento do estudo por meio do Edital BIEXT. 
Economia vai à escola: relatos de extensão em um colégio técnico

\section{REFERÊNCIAS}

BARON, Daniel. et al. Popularização da sustentabilidade: análise de uma integração ensino médiograduação. Revista Brasileira de Extensão Universitária, v. 11, n. 1, p. 97-112, 2020.

BATISTA, Natália Nunes Ferreira; DA SILVA, Roseli. Experimentos Econômicos para Estudantes do Ensino Médio da Rede Pública de Ribeirão Preto/SP. Revista de Cultura e Extensão USP, v. 4, p. 45-56, 2010

BRASIL. Ministério da Educação, Conselho Nacional de Educação câmara de educação básica, Resolução, $\mathbf{n}^{\mathbf{o}}$ 7. 14 de dezembro de 2010a. Disponível em: https: http://portal.mec.gov.br/dmdocuments/rceb007_10.pdf. Acesso em: 05 de dez. 2021.

BRASIL. Decreto $\mathbf{n}^{\mathbf{o}}$ 7.397, de 22 de dezembro de 2010b. Disponível em:http://www.planalto.gov.br/ccivil_03/_ato2007-2010/2010/decreto/d7397.htm. Acesso em: 05 de dez. 2021.

FALCÃO, Nádia Maciel; CALDAS, Edla Cristina Rodrigues. Diálogos sobre a escolha profissional: a aproximação entre o estudante da escola pública de ensino médio e a universidade.

Revista Brasileira de Extensão Universitária, v. 9, n. 3, p. 147-156, 2018.

OCDE. National Strategies for Financial Education: OECD/INFE Policy Handbook, 2015. Disponível em: https://www.oecd.org/daf/fin/financial-education/national-strategies-forfinancial-education-policy-handbook.htm. Acesso em: 05 de dez. 2021

PEROBELLI, Fernanda Finotti Cordeiro et al. Economia nas escolas: relato de uma experiência. VIII SEGeT, 2018.

SANTOS, Leonardo Bis; SGARBI, Antônio Donizetti. Escola e comunidade: pesquisa e extensão em busca da cidadania emancipatória. Revista Brasileira de Extensão Universitária, v. 9, n. 3, p. 135-146, 2018.

UFRRJ. CTUR: Colégio técnico da UFRRJ. Nossa História, 2013 Disponível em: https: http://r1.ufrrj.br/ctur/. Acesso em: 04 de jun. 2020

UFRRJ. Plano de Desenvolvimento Institucional da UFRRJ (2018-2022). Universidade Federal Rural do Rio de Janeiro. Seropédica, RJ: UFRRJ, 2017. 165p.

USP. Projeto da FEA quer alunos do ensino médio pensando a economia. USP Online Destaque. 13 jun. 2014. Disponível em: https://www5.usp.br/44510/projeto-da-fea-quer-alunos-do-ensinomedio-pensando-a-economia/ . Acesso em: 28 de jun. 2020.

Recebido em: 28/07/2020

Aceito em: 14/12/2021 